\title{
A Frequency and Molecular Typing Study of Methicillin-Resistant Staphylococcus aureus Isolates in Teaching Hospitals in Shahrekord, SouthWestern Iran
}

\author{
Roohollah Taghaddosi, ${ }_{1}$ Abolfazl Gholipour,, ${ }^{1, *}$ Marzieh Zeraatpisheh, ${ }^{1}$ Maryam Safarpour-Dehkordi, ${ }^{2}$ \\ Davood Darban-Sarokhalil, ${ }^{3}$ and Fatemeh Heibati-Goujani ${ }^{4}$ \\ ${ }^{1}$ Department of Microbiology and Immunology, Cellular and Molecular Research Center, Shahrekord University of Medical Sciences, Shahrekord, IR Iran \\ ${ }^{2}$ Biotechnology Research Center, Islamic Azad University Shahrekord Branch, Shahrekord, IR Iran \\ ${ }^{3}$ Department of Microbiology, Iran University of Medical Sciences, Tehran, IR Iran \\ ${ }^{4}$ Biochemistry Research Center, Shahrekord University of Medical Sciences, Shahrekord, IR Iran \\ "Corresponding author: Abolfazl Gholipour, Department of Microbiology and Immunology, Cellular and Molecular Research Center, Shahrekord University of Medical \\ Sciences, Shahrekord, IR Iran. Tel: + 98-9137046656, E-mail: abolfazl_gholipour@yahoo.com
}

Received 2016 June 01; Revised 2016 August 24; Accepted 2016 September 04.

\begin{abstract}
Background: Methicillin-resistant Staphylococcus aureus (MRSA) remains a significant public health problem and treatment challenge.

Objectives: This study was conducted to determine the frequency, molecular types, and drug resistance of S. aureus isolated from nasal carriers in two teaching hospitals (Hajar and Kashani) in Shahrekord, southwestern Iran.

Methods: In this cross-sectional study, 262 nasal specimens were obtained from healthcare staff. The disk-diffusion method was used to detect MRSA. Nine antibiotic disks were used to determine the antibiotic susceptibility pattern. Staphylococcal cassette chromosome mec (SCCmec) types were identified by the multiplex polymerase chain reaction (PCR). The data analysis was performed using Fisher's exact test with SPSS software.

Results: Forty-eight (18.8\%) specimens were identified as S. aureus, of which 30 (11.45\%) specimens were methicillin resistant. The nasal colonization rate of the MRSA isolates was not associated with age or gender ( $\mathrm{P}>0.05)$. The highest resistance (33\%) recorded was to rifampin, and all the isolates were susceptible to quinupristin-dalfopristin, vancomycin, and linezolid. The SCCmec results showed that $16.7 \%, 6.7 \%, 20 \%$, and $56.6 \%$ of MRSA isolates were types I, II, III, and IV, respectively.

Conclusions: Nasal isolates of MRSA were prevalent among hospital staff. The highest level of resistance was to rifampin, and all the isolates were susceptible to quinupristin-dalfopristin, vancomycin, and linezolid. SCCmec type 4 was the most frequent MRSA isolate.
\end{abstract}

Keywords: Methicillin-Resistant, Molecular Typing, Drug Resistance, Staphylococcus aureus

\section{Background}

Many species of pathogenic bacteria, including Staphylococcus aureus, have become antibiotic resistant. The potential of $S$. aureus to develop resistance rapidly to many antibiotics has led to the emergence of methicillinresistant $S$. aureus (MRSA) $(1,2)$. Methicillin resistance is associated with the production of the PBP2a protein by the mecA gene. This gene is located on a 30 - $50 \mathrm{~kb}$ chromosomal DNA fragment, which is present in resistant strains but absent in susceptible ones $(2,3)$. The staphylococcal cassette chromosome mec (SCCmec) is a mobile genetic element that carries the mecA gene and other antibioticresistant genes in MRSA strains $(4,5)$. Staphylococcal cassette chromosome mec typing is performed to identify and differentiate community-associated MRSA infections from healthcare-associated ones. Staphylococcal cassette chro- mosome mec typing has been widely used to identify several subtypes or variants of the main SCCmec types. Staphylococcal cassette chromosome mec typing using the multiplex polymerase chain reaction (PCR) is a simple method that can be applied in clinical microbiology laboratories $(6,7)$.

Approximately $44 \%$ of nosocomial infections worldwide are estimated to be due to MRSA (8). Moreover, MRSA is associated with excessively high healthcare costs in many countries. For example, annual costs to deal with the consequences of MRSA in the U.S. are estimated at over 13.8-billion dollars $(9,10)$. The prevalence of MRSA continues to increase among healthcare staff, with a high rate of nasal colonization by MRSA reported (11). Methicillin resistant $S$. aureus can be transmitted via the skin and hands of healthcare staff through the nostrils and lead to infection 
and a variety of complications in patients (12). MRSA infection can result in severe complications, such as endocarditis, septicemia, pneumonia, and osteomyelitis (13-15).

Restrictions placed on drug treatment due to MRSA have made it more difficult to combat nosocomial and community-acquired infections (16-18). The transmission of MRSA to patients via the hands or nostrils of healthcare staff can result in hospitalized patients experiencing major problems (19). Methicillin resistant S. aureus infections among healthcare staff remain high, and the treatment and hospitalization costs of MRSA-infected patients are enormous. Therefore, strategies to control the spread of MRSA are needed (20). Given the importance of the prevention and treatment of nosocomial infections, data are needed on the incidence rate, prevalence, antibiotic resistance, and bacterial typing of MRSA.

\section{Objectives}

This study was conducted to determine the frequency, molecular types, and drug resistance of $S$. aureus nasal isolates in two teaching hospitals in Iran using PCR and diskdiffusion methods.

\section{Methods}

\subsection{Specimen Collection and Bacterial Identification}

After obtaining ethical approval for the study from the ethics committee of Shahrekord University of Medical Sciences (Grant No. 1184), 262 people were enrolled in the study: 149 staff from Kashani hospital and 113 staff from Hajar hospital. The occupational categories consisted of physicians, nurses, health workers, technicians, administrative staff, and service personnel from the surgical ward, intensive care unit, kitchen, and laundry room.

To ensure qualitative and quantitative standardization in the study, one individual collected all the samples and recorded the data. The nasal specimens were collected from the anterior nares of the participants using labeled sterile cotton wool swabs. The specimens were immediately transferred to trypticase soy broth medium and incubated at $37^{\circ} \mathrm{C}$ for 24 hours. The specimens were cultured in blood agar and mannitol salt agar media (Hi Media, India) in the laboratory. If the colony became yellow in the mannitol salt agar medium, gram staining was conducted. To differentiate Staphylococcus spp. in gram-positive cluster-forming cocci, catalase and coagulase (with rabbit plasma) production tests were conducted, as well as DNase activity tests on DNase agar (Hi Media, India) and novobiocin susceptibility tests $(21,22)$. To detect MRSA isolates, oxacillin $(1 \mu \mathrm{g})$ disk (Hi Media, India) diffusion testing was performed. To determine the antibiotic susceptibility of the isolates, eight antibiotic disks (gentamicin, linezolid, vancomycin, rifampin, novobiocin, ticoplanin, tigecycline, and quinopristin-dalfopristin) obtained from Hi Media (India) were tested using the Kirby-Bauer disk-diffusion method (23).

\subsection{DNA Extraction}

Total DNA was extracted from the bacteria that grew on the culture media with a genomic DNA purification kit (CinnaGen Co., Iran, according to the manufacturer's instructions. The quality of the extracted DNA was measured at $260 \mathrm{~nm}$ wavelength according to Sambrook and Russell's method (24). The extracted DNA was stored at $-20^{\circ} \mathrm{C}$ for later use.

\subsection{MultiplexPCRAssay for Assignment of the mec Element Type}

A multiplex PCR assay was used to identify the MRSA isolates. The multiplex PCR method is a rapid, accurate, and useful assay to detect the mecA gene in MRSA strains, particularly in a hospital setting (25).

The multiplex PCR included eight loci, A-H, selected based on mec element sequences (Table 1) (26). The mecA gene was also included in this protocol. The PCR reactions were conducted in a total volume of $25 \mu \mathrm{L}$ containing the following: $2 \mu \mathrm{L}$ of DNA sample, $2.5 \mu \mathrm{l}$ of $10 \times$ PCR buffer, 2 $\mu \mathrm{L}$ of mixed dNTP, $2.5 \mu \mathrm{L}$ of $\mathrm{MgCl}_{2}, 0.5 \mu \mathrm{L}$ of DNA Taq polymerase, and $0.5 \mu \mathrm{L}$ of primers $\mathrm{A}$ and $\mathrm{D}$ for type I; primers $\mathrm{B}$, C, D, and G for type II; primers C, E, F, and H for type III, and primers D and I for type IV. The PCR assay was performed in a DNA Thermal Cycler 480 (Applied Biosystems, U.S.) using the following parameters: denaturation for $5 \mathrm{~min}$ at $95^{\circ} \mathrm{C} ; 35$ cycles of $94^{\circ} \mathrm{C}$ for 45 seconds, $53^{\circ} \mathrm{C}$ for 40 seconds, and $72^{\circ} \mathrm{C}$ for 1 minutes, followed by a final extension for 7 minutes at $72^{\circ} \mathrm{C}$. For type IV, the annealing temperature was $52^{\circ} \mathrm{C}$ for 50 seconds. The PCR products then underwent polyacrylamide gel ( $8 \%$ ) electrophoresis and staining with silver nitrate.

\subsection{Statistical Analysis}

The data were analyzed using Fisher's exact test with SPSS, version 16 (SPSS Inc., U.S.). The level of significance was considered as 0.05 .

\section{Results}

In total, the presence of MRSA in 262 samples was tested. Of the 148 samples from Kashani hospital, 76 (51\%) were from males. Of the 114 samples from Hajar hospital, 48 (43\%) were from males. Fisher's exact test indicated no 
Table 1. Primers Used in the Multiplex Polymerase Chain Reaction ${ }^{\mathrm{a}}$

\begin{tabular}{|c|c|c|c|c|c|}
\hline Locus & Primer & Oligonucleotide Sequence (5’ - 3') & Location & Amplicon Size, bp & $\begin{array}{c}\text { Specificity, SCCmec } \\
\text { Type }\end{array}$ \\
\hline \multirow{2}{*}{ A } & CIF2 F2 & TTCGAGTTGCTGATGAAGAAGG & $18398-18419^{\mathrm{b}}$ & \multirow{2}{*}{495} & \multirow{2}{*}{ I } \\
\hline & CIF2 R2 & ATTTACCACAAGGACTACCAGC & $18892-18871^{\mathrm{b}}$ & & \\
\hline \multirow{2}{*}{ B } & KDP F1 & AATCATCTGCCATTGGTGATGC & $10445-10467^{c}$ & \multirow{2}{*}{284} & \multirow{2}{*}{ II } \\
\hline & KDP R1 & CGAATGAAGTGAAAGAAAGTGG & $10728-10707^{c}$ & & \\
\hline \multirow{2}{*}{ C } & MECI P2 & ATCAAGACTTGCATTCAGGC & $42428-42447^{\mathrm{c}}$ & \multirow{2}{*}{209} & \multirow{2}{*}{ II, III } \\
\hline & MECI P3 & GCGGTTTCAATTCACTTGTC & $42636-42617^{c}$ & & \\
\hline \multirow{2}{*}{ D } & DCS F2 & CATCCTATGATAGCTTGGTC & $38011-37992^{\mathrm{b}}$ & \multirow{2}{*}{342} & \multirow{2}{*}{ I, II, IV } \\
\hline & DCS R1 & CTAAATCATAGCCATGACCG & $37670-37689^{b}$ & & \\
\hline \multirow{2}{*}{$\mathbf{E}$} & RIF4 F3 & GTGATTGTTCGAGATATGTGG & $45587-45607^{d}$ & \multirow{2}{*}{243} & \multirow{2}{*}{ III } \\
\hline & RIF4 R9 & CGCTTTATCTGTATCTATCGC & $45829-45809^{d}$ & & \\
\hline $\mathbf{F}$ & RIF5 F10 & TTCTTAAGTACACGCTGAATCG & $59573-59594^{d}$ & 414 & III \\
\hline \multirow{2}{*}{ G } & IS431 P4 & CAGGTCTCTTCAGATCTACG & $49963-49982^{c}$ & \multirow{2}{*}{381} & \multirow{2}{*}{ II } \\
\hline & pUB110 R1 & GAGCCATAAACACCAATAGCC & $50343-50323^{c}$ & & \\
\hline \multirow{2}{*}{$\mathbf{H}$} & IS431 P4 & CAGGTCTCTTCAGATCTACG & $29654-29673^{\mathrm{d}}$ & \multirow{2}{*}{303} & \multirow{2}{*}{ III } \\
\hline & pT181 R1 & GAAGAATGGGGAAAGCTTCAC & $29976-29956^{d}$ & & \\
\hline \multirow{2}{*}{ mecA } & MECA P4 & TCCAGATTACAACTTCACCAGG & $1190-1211^{\mathrm{e}}$ & \multirow{2}{*}{162} & \multirow{2}{*}{ Internal control } \\
\hline & MECA P7 & CCACTTCATATCTTGTAACG & $1351-1332^{\mathrm{e}}$ & & \\
\hline
\end{tabular}

${ }^{a}$ Loci $G$ and $H$ were included to distinguish variants IA from I and IIIA from III, respectively.

${ }^{\mathrm{b}}$ Relative to accession No. AB033763, SCCmec type I

${ }^{c}$ Relative to accession No. D86934, SCCmec type II

Relative to accession No. AB037671, SCCmec type III

${ }^{\mathrm{e}}$ Relative to accession No. Yo0688, mecA gene

significant association between gender and the colonization rate of the MRSA isolates $(\mathrm{P}=0.218)$. The mean age of the participants from Hajar and Kashani hospitals was 31.5 \pm 20 and $32 \pm 12$ (range: 21 - 51 and 21 - 45) years, respectively. In addition, Fisher's exact test indicated no significant association between age and the colonization rate of the MRSA isolates $(\mathrm{P}=0.658)$. The proportion, age, and gender of the S. aureus-positive participants are shown in Table 2.

Nineteen of the 148 (12.8\%) isolates from Kashani hospital were identified as S. aureus, of which 12 (63\% [ $8 \%$ of total isolates]) were MRSA. In Hajar hospital, 29 of the 114 isolates were identified as S. aureus, of which 18 (62\% [15.7\% of total isolates]) were MRSA (Figure 1). Based on a coagulasepositive test, S. aureus was detected in 48 samples (18\%). In the oxacillin disk-diffusion test of the methicillin resistance of the coagulase-positive isolates, 30 of the $48 \mathrm{~S}$. aureus isolates were MRSA.

To determine the prevalence of MRSA carriers among staff with different occupations in the hospitals, the participants were divided into three groups (physicians, nurses, and nontreatment). The latter consisted of service personnel, kitchen staff, office staff (secretaries and administrators), and guardians. In Hajar hospital, nurses (50\%) ac-

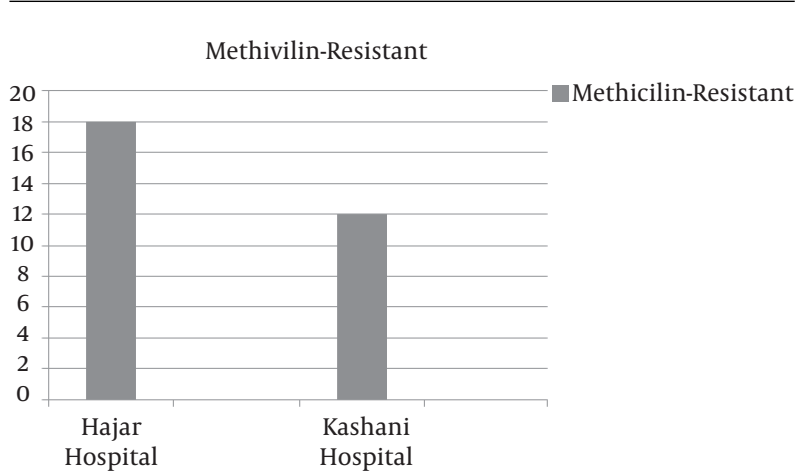

Figure 1. Prevalence of Methicillin-Resistant Staphylococcus aureus in Each Hospital

counted for the highest proportion of carriers, and nontreatment staff accounted for the lowest proportion (22\%). In Kashani hospital, nurses also comprised the highest proportion (41\%) of carriers, and nontreatment staff comprised the lowest proportion (8\%).

According to the antibiotic susceptibility analysis, the highest resistance obtained was to rifampin (33\%), and all the isolates were susceptible to quinupristin-dalfopristin vancomycin, and linezolid. Table 3 summarizes the an- 
Table 2. Demographic Characteristics of the Methicillin-Resistant Staphylococcus aureus-Positive Participants

\begin{tabular}{|c|c|c|c|c|}
\hline Variable & \multicolumn{2}{|c|}{ Gender } & \multicolumn{2}{|c|}{ Age } \\
\hline Group & Female & Male & $\leq 50$ & $>50$ \\
\hline Frequency & 18 & 30 & 42 & 6 \\
\hline$\%$ & 37.5 & 62.5 & 87.5 & 12.5 \\
\hline
\end{tabular}

tibiotic susceptibility pattern of the MRSA isolates. The mecA gene was detected in all the MRSA isolates by the PCR. The results of SCCmec typing based on the multiplex PCR method showed that of 30 tested isolates, five (16.7\%) were type I, two (6.7\%) were type II, six (20\%) were type III, and seventeen (56.6\%) were type IV MRSA (Figure 2 ). Figure 3 shows the SCCmec types of methicillin-resistant isolates detected in the two hospitals.

\section{Discussion}

The present study was conducted to determine the frequency and molecular types of MRSA isolated from nasal carriers in teaching hospitals in Shahrekord. In this study, 48 of 262 (18\%) samples were identified as S. aureus, of which 30 (11.45\%) were MRSA. In different studies of nasal samples obtained from healthcare staff, the prevalence of MRSA was reported to be $6.2 \%, 12.7 \%, 13.95 \%, 14.3 \%, 6.7 \%$, and $18 \%$ in France, Ethiopia, Pakistan, India, and Saudi Arabia, respectively (27-32). Various prevalence rates (5.3 - 53.8\%) of MRSA have been reported for Staphylococcus species isolated from individuals in different regions of Iran and from individuals in different occupations $(33,34)$. The different prevalence rates of this pathogen can be attributed to dissimilarities in healthcare policies (pattern of medication use), sample collection, nosocomial infection control, and the performance, education, and adherence of healthcare staff to hygiene-related recommendations, all of which potentially contribute to the distribution of resistant strains, including MRSA (30, 35-39).

In the present study, the colonization rate of MRSA isolates was not associated with age or gender. A previous study of the prevalence and antibiotic susceptibility pattern of nasal samples obtained from hospital staff and analyzed using the PCR method also found no significant difference in the carriage of this pathogen according to age and gender (33). However, Diawara et al. reported that age was significantly associated with being a carrier of this pathogen (40). Gebreyesus et al. demonstrated that women were more frequent carriers of the pathogen than men and that this finding was statistically significant (41). Several factors, such as the methodology of the study and occupational setting, may have contributed to these associations.
Nurses comprised 50\% of the MRSA carriers in the present study. In other studies, nurses were also reported to be the most frequent carriers of MRSA $(30,32,41,42)$. The fact that nurses have more frequent contact with patients than other healthcare staff do and that they provide care to patients in different wards throughout the hospital likely explains this finding. As a result, nurses may have a greater risk than other staff of acquiring communityacquired MRSA. Therefore, the higher rate of MRSA acquisition among the nurses in the present study is not surprising.

Among methicillin-resistant isolates, the highest resistance was to rifampin, and all the isolates were susceptible to quinipristin-dalfupristine, vancomycin, and linzolid. In a previous study, $64.1 \%$ of MRSA isolates were resistant to amikacin, and $76.92 \%, 51.28 \%, 87.18 \%, 71.8 \%, 10.26 \%$, $5.13 \%, 89.74 \%$, and $61.54 \%$ were resistant to ceftriaxone, ciprofloxacin, erythromycin, gentamicin, mupirocin, rifampin, tetracycline, and tobramycin, respectively (43). In the same study, all the MRSA and methicillin-susceptible $S$. aureus isolates were susceptible to fusidic acid, linezolid, teicoplanin, tigecycline, and vancomycin (43). In another study, MRSA isolates also appeared to exhibit high sensitivity to vancomycin, teicoplanin, and trimethoprim/sulfamethoxazole (44). Various factors, such as age, duration of treatment, and geographical region, have been shown to contribute to MRSA drug resistance $(36,45,46)$. The results of the SCCmec typing in the present study demonstrated that $16.7 \%$ of MRSA isolates were type I, $6.7 \%$ were type II, $20 \%$ were type III, and $56.6 \%$ were type IV.

In a study of specimens obtained in a hospital setting, a PCR analysis revealed that SCCmec type I was the most frequent type (58.9\%), followed by SCCmec type II (19.9\%), type III (11.0\%), and type IV (8.2\%) (35). In another study, most isolates were SCCmec types II and IV (47). In a study of isolates obtained from healthcare staff, approximately half the specimens were types IVa and V, and no specimens were type I (48).

The prevalence of MRSA among healthcare staff in the two hospitals in southwestern Iran varied, and the estimated prevalence was lower than average. The findings indicated that the MRSA isolates showed the highest resistance to rifampin and that all the isolates were susceptible to quinipristin-dalfupristine, vancomycin, and lin- 
Table 3. Antibiotic Susceptibility Pattern of Methicillin-Resistant Staphylococcus aureus Isolates

\begin{tabular}{|c|c|c|c|}
\hline Antibiotic & Susceptible, No. (\%) & Intermediate, No. (\%) & Resistant, No. (\%) \\
\hline Bacitracin, $10 \mu \mathrm{g}$ & $24(80)$ & 0 & $6(20)$ \\
\hline Gentamycin, $10 \mu \mathrm{g}$ & $26(86.7)$ & 0 & $4(13.3)$ \\
\hline Novobiocin, $30 \mu \mathrm{g}$ & $25(83)$ & $1(3)$ & $4(13.3)$ \\
\hline Ticoplanin, $30 \mu \mathrm{g}$ & $18(60)$ & $5(17)$ & $7(23)$ \\
\hline Linezolid, $30 \mu \mathrm{g}$ & $30(100)$ & 0 & 0 \\
\hline Quinupristin-dalfopristin, $15 \mu \mathrm{g}$ & $30(100)$ & 0 & 0 \\
\hline Tigecycline, $15 \mu \mathrm{g}$ & $17(56.7)$ & $4(13.3)$ & $9(30)$ \\
\hline Rifampin, $5 \mu \mathrm{g}$ & $19(63.4)$ & $1(3.3)$ & $10(33.3)$ \\
\hline Vancomycin, $30 \mu \mathrm{g}$ & $30(100)$ & 0 & 0 \\
\hline
\end{tabular}

Figure 2. View of the Stained Polyacrylamide Gel Showing Staphylococcal Cassette Chromosome mec (SCCmec) Types I-IV

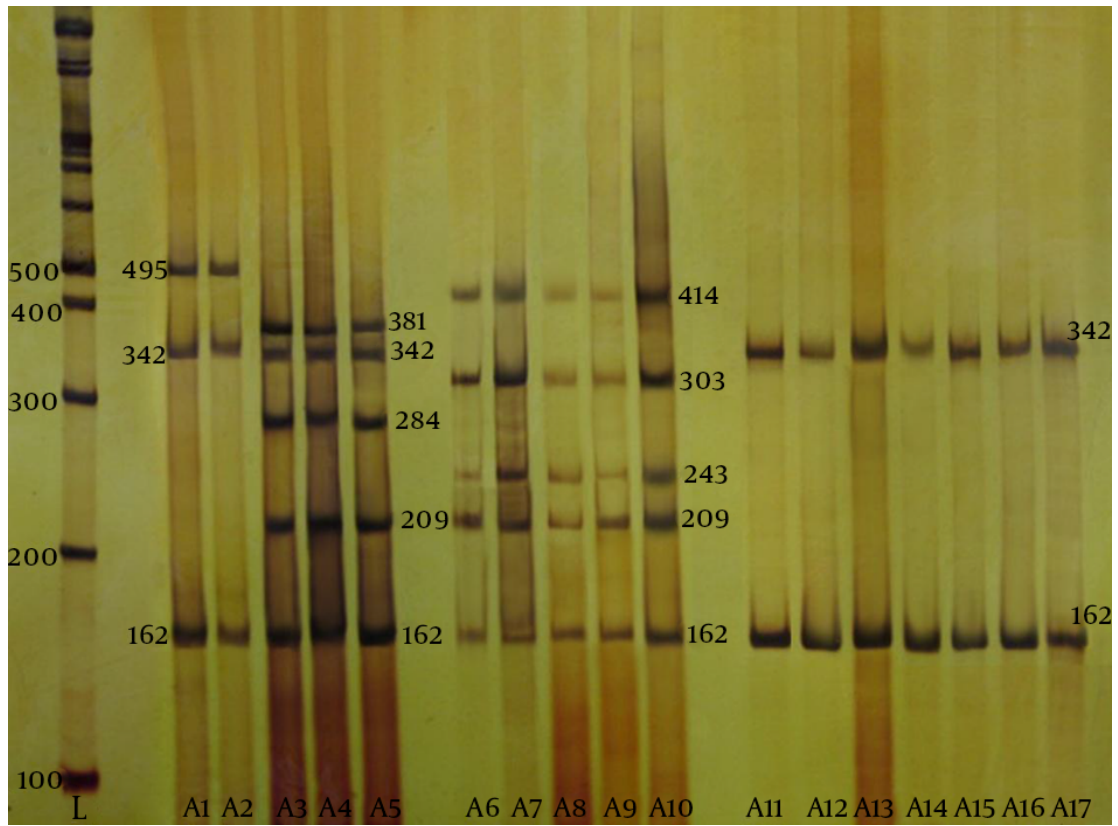

From left to right, first lane, DNA marker; lane A1, standard SCCmec type 1; lane A2, SCCmec type 1; lane A3, standard SCCmec type 2; lanes A4 and A5, SCCmec type 2; lane A6, standard SCCmec type 3; lanes A7 to A10, SCCmec type 3; lane A11, standard SCCmec type IV; lanes A12 to A17, SCCmec type IV.

zolid. SCCmec type IV was the most prevalent MRSA isolate. Given the growth in the resistance of these bacteria to antibiotics, including methicillin, implementing plans to detect, control, and restrict carriers of MRSA, particularly healthcare staff who are in direct contact with patients, is vital to prevent the transmission of MRSA isolates to hospitalized patients.

\section{Acknowledgments}

We are grateful to the research and technology deputy of Shahrekord University of Medical Sciences for funding this study (Grant No. 1184).

\section{Footnotes}

Authors' Contribution: Roohollah Taghaddosi contributed to drafting the manuscript and assisted in conducting the experiments. Maryam Safarpour Dehkordi and Marzieh Zeraatpisheh contributed to drafting the manuscript. Abolfazl Gholipour contributed to the design of the study and data analysis and revised the final version of the manuscript. Davood Darban Sarokhalil contributed to the data analysis and revised the final version of the manuscript. Fatemeh Heibati Goujani assisted in conducting the experiments.

Funding/Support: Research and technology deputy of 


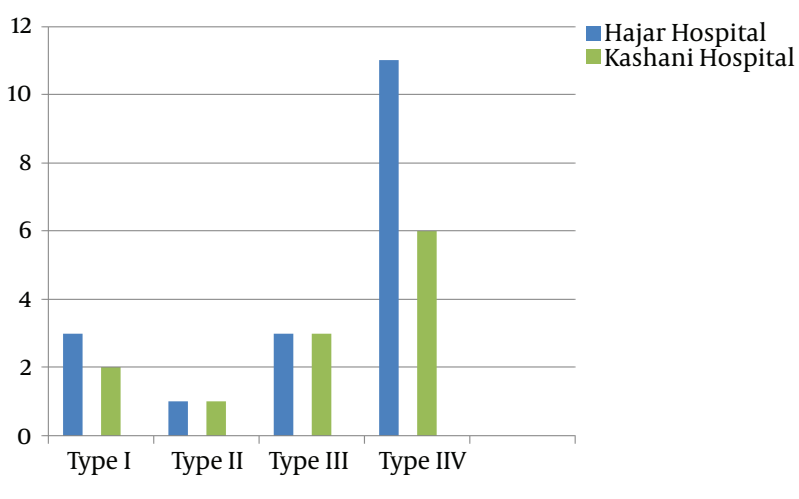

Figure 3. Staphylococcal Cassette Chromosome mec Typing Results for MethicillinResistant Packaging Samples in Each Hospital

Shahrekord University of Medical Sciences, Shahrekord, IR Iran (Grant No. 1184).

\section{References}

1. Chambers HF, Deleo FR. Waves of resistance: Staphylococcus aureus in the antibiotic era. Nat Rev Microbiol. 2009;7(9):629-41. doi: 10.1038/nrmicro2200. [PubMed: 19680247].

2. Peacock SJ, Paterson GK. Mechanisms of Methicillin Resistance in Staphylococcus aureus. Annu Rev Biochem. 2015;84:577-601. doi: 10.1146/annurev-biochem-060614-034516. [PubMed: 26034890].

3. Pantosti A, Sanchini A, Monaco M. Mechanisms of antibiotic resistance in Staphylococcus aureus. Future Microbiol. 2007;2(3):323-34. doi: 10.2217/17460913.2.3.323. [PubMed: 17661706].

4. Zhang K, McClure JA, Elsayed S, Louie T, Conly JM. Novel multiplex PCR assay for characterization and concomitant subtyping of staphylococcal cassette chromosome mec types I to V in methicillin-resistant Staphylococcus aureus. J Clin Microbiol. 2005;43(10):5026-33. doi: 10.1128/JCM.43.10.5026-5033.2005. [PubMed: 16207957].

5. Hanssen AM, Ericson Sollid JU. SCCmec in staphylococci: genes on the move. FEMS Immunol Med Microbiol. 2006;46(1):8-20. doi:10.1111/j.1574695X.2005.00009.x. [PubMed: 16420592].

6. Ghaznavi-Rad E, Nor Shamsudin M, Sekawi Z, van Belkum A, Neela V. A simplified multiplex PCR assay for fast and easy discrimination of globally distributed staphylococcal cassette chromosome mec types in meticillin-resistant Staphylococcus aureus. J Med Microbiol. 2010;59(Pt 10):1135-9. doi: 10.1099/jmm.0.021956-0. [PubMed: 20616192].

7. Milheirico C, Oliveira DC, de Lencastre H. Multiplex PCR strategy for subtyping the staphylococcal cassette chromosome mec type IV in methicillin-resistant Staphylococcus aureus: 'SCCmec IV multiplex'.JAntimicrob Chemother. 2007;60(1):42-8. doi:10.1093/jac/dkm112. [PubMed: 17468509].

8. Kock R, Becker K, Cookson B, van Gemert-Pijnen JE, Harbarth S, Kluytmans J, et al. Methicillin-resistant Staphylococcus aureus (MRSA): burden of disease and control challenges in Europe. Euro Surveill. 2010;15(41):19688. [PubMed: 20961515].

9. Gould IM, Reilly J, Bunyan D, Walker A. Costs of healthcare-associated methicillin-resistant Staphylococcus aureus and its control. Clin Microbiol Infect. 2010;16(12):1721-8. doi: 10.1111/j.1469-0691.2010.03365.x. [PubMed: 20825434].

10. Lee BY, Singh A, David MZ, Bartsch SM, Slayton RB, Huang SS, et al. The economic burden of community-associated methicillinresistant Staphylococcus aureus (CA-MRSA). Clin Microbiol Infect.
2013;19(6):528-36. doi: 10.1111/j.1469-0691.2012.03914.x. [PubMed: 22712729].

11. Elie-Turenne MC, Fernandes H, Mediavilla JR, Rosenthal M, Mathema B, Singh A, et al. Prevalence and characteristics of Staphylococcus aureus colonization among healthcare professionals in an urban teaching hospital. Infect Control Hosp Epidemiol. 2010;31(6):574-80. doi: 10.1086/652525. [PubMed: 20426580].

12. Aires De Sousa M, Santos Sanches I, Ferro ML, De Lencastre H. Epidemiological study of staphylococcal colonization and cross-infection in two West African Hospitals. Microb Drug Resist. 2000;6(2):133-41. doi: 10.1089/107662900419447. [PubMed: 10990268].

13. Bassetti M, Trecarichi EM, Mesini A, Spanu T, Giacobbe DR, Rossi $\mathrm{M}$, et al. Risk factors and mortality of healthcare-associated and community-acquired Staphylococcus aureus bacteraemia. Clin Microbiol Infect. 2012;18(9):862-9. doi: 10.1111/j.1469-0691.2011.03679.x. [PubMed: 21999245].

14. Townell NJ, Munckhof WJ, Nimmo G, Bannan A, Holley A, Daniel $A$, et al. Community-associated methicillin-resistant Staphylococcus aureus endocarditis 'down under': case series and literature review. Scand J Infect Dis. 2012;44(7):536-40. doi 10.3109/00365548.2012.664779. [PubMed: 22404422].

15. Tattevin P, Schwartz BS, Graber CJ, Volinski J, Bhukhen A, Bhukhen A, et al. Concurrent epidemics of skin and soft tissue infection and bloodstream infection due to community-associated methicillinresistant Staphylococcus aureus. Clin Infect Dis. 2012;55(6):781-8. doi: 10.1093/cid/cis527. [PubMed: 22670044].

16. Otter JA, French GL. Molecular epidemiology of communityassociated meticillin-resistant Staphylococcus aureus in Europe. Lancet Infect Dis. 2010;10(4):227-39. doi: 10.1016/S1473-3099(10)700530. [PubMed: 20334846].

17. Cimolai N. Methicillin-resistant Staphylococcus aureus in Canada: a historical perspective and lessons learned. Can I Microbiol. 2010;56(2):89-120. doi: 10.1139/w09-109. [PubMed: 20237572].

18. David MZ, Daum RS. Community-associated methicillin-resistant Staphylococcus aureus: epidemiology and clinical consequences of an emerging epidemic. Clin Microbiol Rev. 2010;23(3):616-87. doi: 10.1128/CMR.00081-09. [PubMed: 20610826].

19. Hosainzadegan H, Menati S, Tarahi M, Mohammadi F. Methicillin and vancomycin-resistant Staphylococcus aureus colonization frequency among hospital staff shohada Khorramabad. J Med Lab Sci. 2008;2(1):26-32.

20. Farr BM, Jarvis WR. Would active surveillance cultures help control healthcare-related methicillin-resistant Staphylococcus aureus infections?. Infect Control Hosp Epidemiol. 2002;23(2):65-8. doi: 10.1086/502008. [PubMed: 11893150].

21. Reisner SB, Woods GL, Thomson RP. Specimen collection. In: Murray PR, Baron EJ, Pfaller MA, Tenover FC, Yolken R. H. , editors. Manual of Clinical Microbiology. Washington: American Society for Microbiology; 1999. pp. 64-76.

22. Pezzlo MT, Amsterdam D, Anhalt JP, Lawrence T, Stratton NJ, Vetter EA, et al. Detection of bacteriuria and pyuria by URISCREEN a rapid enzymatic screening test. J Clin Microbiol. 1992;30(3):680-4. [PubMed: 1551986].

23. Khan RA, Rahman AU, Ahmad A, Jaseem M, Jabbar A, Khan SA, et al. Prevalence and Antibiotic Susceptibility Profile of MethicillinResistant Staphylococcus aureus (MRSA) Isolated from Different Clinical Samples in District Peshawar.JAppl Environ Biol Sci. 2014;4(8S):406.

24. Sambrook J, Russell DW. Molecular cloning: a laboratory manual 3rd edition. UK: Coldspring-Harbour Laboratory Press; 2001.

25. Pournajaf A, Ardebili A, Goudarzi L, Khodabandeh M, Narimani T, Abbaszadeh H. PCR-based identification of methicillin-resistant Staphylococcus aureus strains and their antibiotic resistance profiles. Asian Pac J Trop Biomed. 2014;4(Suppl 1):S293-7. doi 10.12980/APJTB.4.2014C423. [PubMed: 25183100]. 
26. Oliveira DC, de Lencastre H. Multiplex PCR strategy for rapid identification of structural types and variants of the mec element in methicillin-resistant Staphylococcus aureus. Antimicrob Agents Chemother. 2002;46(7):2155-61. [PubMed: 12069968].

27. Eveillard M, Martin Y, Hidri N, Boussougant Y, Joly-Guillou ML. Carriage of methicillin-resistant Staphylococcus aureus among hospital employees: prevalence, duration, and transmission to households. Infect Control Hosp Epidemiol. 2004;25(2):114-20. doi: 10.1086/502360. [PubMed: 14994935].

28. Zakai SA. Prevalence of methicillin-resistant Staphylococcus aureus nasal colonization among medical students in Jeddah, Saudi Arabia. Saudi Med J. 2015;36(7):807-12. doi: 10.15537/smj.2015.7.11609. [PubMed: 26108584].

29. Shibabaw A, Abebe T, Mihret A. Nasal carriage rate of methicillin resistant Staphylococcus aureus among Dessie Referral Hospital Health Care Workers; Dessie, Northeast Ethiopia. Antimicrob Resist Infect Control. 2013;2(1):25. doi: 10.1186/2047-2994-2-25. [PubMed: 24088259].

30. Rashid Z, Farzana K, Sattar A, Murtaza G. Prevalence of nasal Staphylococcus aureus and methicillin-resistant Staphylococcus aureus in hospital personnel and associated risk factors. Acta Pol Pharm. 2012;69(5):985-91. [PubMed: 23061297].

31. M R, D'Souza M, Kotigadde S, Saralaya KV, Kotian MS. Prevalence of Methicillin Resistant Staphylococcus aureus Carriage amongst Health Care Workers of Critical Care Units in Kasturba Medical College Hospital, Mangalore, India. J Clin Diagn Res. 2013;7(12):2697-700. doi: 10.7860/JCDR/2013/5160.3735. [PubMed: 24551616].

32. Al-Humaidan OS, El-Kersh TA, Al-Akeel RA. Risk factors of nasal carriage of Staphylococcus aureus and methicillin-resistant Staphylococcus aureus among health care staff in a teaching hospital in central Saudi Arabia. Saudi Med J. 2015;36(9):1084-90. doi: 10.15537/smj.2015.9.12460. [PubMed: 26318466].

33. Askarian M, Zeinalzadeh A, Japoni A, Alborzi A, Memish ZA. Prevalence of nasal carriage of methicillin-resistant Staphylococcus aureus and its antibiotic susceptibility pattern in healthcare workers at Namazi Hospital, Shiraz, Iran. Int J Infect Dis. 2009;13(5):241-7. doi: 10.1016/j.ijid.2008.11.026. [PubMed: 19269873].

34. Taherikalani M, Mohammadzad MR, Soroush S, Maleki MH, AziziJalilian F, Pakzad I, et al. Determining the prevalence of SCCmec polymorphism, virulence and antibiotic resistance genes among methicillin-resistant Staphylococcus aureus (MRSA) isolates collected from selected hospitals in west of Iran. J Chemother. 2016;28(2):104-9. doi: 10.1179/1973947815Y.0000000018. [PubMed: 25976554].

35. Rhee Y, Aroutcheva A, Hota B, Weinstein RA, Popovich KJ. Evolving Epidemiology of Staphylococcus aureus Bacteremia. Infect Control Hosp Epidemiol. 2015;36(12):1417-22. doi:10.1017/ice.2015.213. [PubMed: 26372679].

36. Ebrahim-Saraie HS, Motamedifar M, Sarvari J, Hoseini Alfatemi SM. Emergence of SCCmec Type I Obtained From Clinical Samples in Shiraz Teaching Hospitals, South-West of Iran. Jundishapur J Microbiol. 2015;8(6):16998. doi: 10.5812/jjm.16998v2. [PubMed: 26322200].

37. Akhtar N. Staphylococcal nasal carriage of health care workers. $J$
Coll Physicians Surg Pak. 2010;20(7):439-43. doi: 07.2010/JCPSP.439443. [PubMed: 20642942].

38. Balbale SN, Hill JN, Guihan M, Hogan TP, Cameron KA, Goldstein B, et al. Evaluating implementation of methicillin-resistant Staphylococcus aureus (MRSA) prevention guidelines in spinal cord injury centers using the PARIHS framework: a mixed methods study. Implement Sci. 2015;10:130. doi: 10.1186/s13012-015-0318-x. [PubMed: 26353798].

39. Kullar R, Vassallo A, Turkel S, Chopra T, Kaye KS, Dhar S. Degowning the controversies of contact precautions for methicillin-resistant Staphylococcus aureus: A review. Am J Infect Control. 2016;44(1):97-103. doi: 10.1016/j.ajic.2015.08.003. [PubMed: 26375351].

40. Diawara I, Bekhti K, Elhabchi D, Saile R, Elmdaghri N, Timinouni M, et al. Staphylococcus aureus nasal carriage in hemodialysis centers of Fez, Morocco. Iran J Microbiol. 2014;6(3):175-83. [PubMed: 25870751].

41. Gebreyesus A, Gebre-Selassie S, Mihert A. Nasal and hand carriage rate of methicillin resistant Staphylococcus aureus (MRSA) among health care workers in Mekelle Hospital, North Ethiopia. Ethiop Med J. 2013;51(1):41-7. [PubMed: 23930490].

42. Ohadian Moghadam S, Pourmand MR, Davoodabadi A. The Detection of Mupirocin Resistance and Nasal Carriage of Methicillin Resistant Staphylococcus aureus among Healthcare Workers at University Hospitals of Tehran, Iran. Iran J Public Health. 2015;44(3):361-8. [PubMed: 25905079].

43. Ohadian Moghadam S, Pourmand MR, Aminharati F. Biofilm formation and antimicrobial resistance in methicillin-resistant Staphylococcus aureus isolated from burn patients, Iran. J Infect Dev Ctries. 2014;8(12):1511-7. doi: 10.3855/jidc.5514. [PubMed: 25500648].

44. Kim SH, Kim MG, Kim SS, Cha SH, Yeo SG. Change in Detection Rate of Methicillin-Resistant Staphylococcus aureus and Pseudomonas aeruginosa and Their Antibiotic Sensitivities in Patients with Chronic Suppurative Otitis Media. J Int Adv Otol. 2015;11(2):151-6. doi: 10.5152/iao.2015.1106. [PubMed: 26381007].

45. Jung MY, Chung JY, Lee HY, Park J, Lee DY, Yang JM. Antibiotic Susceptibility of Staphylococcus aureus in Atopic Dermatitis: Current Prevalence of Methicillin-Resistant Staphylococcus aureus in Korea and Treatment Strategies. Ann Dermatol. 2015;27(4):398-403. doi: 10.5021/ad.2015.27.4.398. [PubMed: 26273155].

46. Popovich KJ, Smith KY, Khawcharoenporn T, Thurlow CJ, Lough J, Thomas G, et al. Community-associated methicillin-resistant Staphylococcus aureus colonization in high-risk groups of HIV-infected patients. Clin Infect Dis. 2012;54(9):1296-303. doi: 10.1093/cid/cis030. [PubMed: 22354926].

47. Lee CS, Montalmont B, O'Hara JA, Syed A, Chaussard C, McGaha TL, et al. Screening for methicillin-resistant Staphylococcus aureus colonization using sponges. Infect Control Hosp Epidemiol. 2015;36(1):28-33. doi: 10.1017/ice.2014.4. [PubMed: 25627758].

48. Adwan K, Jarrar N, Abu-Hijleh A, Adwan G, Awwad E, Salameh Y. Molecular analysis and susceptibility patterns of methicillin-resistant Staphylococcus aureus strains causing community- and health careassociated infections in the northern region of Palestine. Am J Infect Control. 2013;41(3):195-8. doi: 10.1016/j.ajic.2012.03.040. [PubMed: 22998783]. 